\title{
Hydrogen Storage Properties of Mg Alloy Prepared by Incorporating Polyvinylidene Fluoride via Reactive Milling
}

\author{
Myoung Youp Song and Young Jun Kwak* \\ Division of Advanced Materials Engineering, Hydrogen \& Fuel Cell Research Center, Engineering Research Institute, \\ Chonbuk National University, Jeonju 54896, Republic of Korea
}

\begin{abstract}
In the present work, we selected a polymer, polyvinylidene fluoride (PVDF), as an additive to improve the hydrogenation and dehydrogenation properties of $\mathrm{Mg} .95 \mathrm{wt} \% \mathrm{Mg}+5 \mathrm{wt} \% \mathrm{PVDF}$ (designated Mg-5PVDF) samples were prepared via milling in hydrogen atmosphere (reactive milling), and the hydrogenation and dehydrogenation characteristics of the prepared samples were compared with those of $\mathrm{Mg}$ milled in hydrogen atmosphere. The dehydrogenation of magnesium hydride formed in the as-prepared Mg$5 \mathrm{PVDF}$ during reactive milling began at $681 \mathrm{~K}$. In the fourth cycle $(\mathrm{n}=4)$, the initial hydrogenation rate was $0.75 \mathrm{wt} \% \mathrm{H} / \mathrm{min}$ and the quantity of hydrogen absorbed for $60 \mathrm{~min}, \mathrm{H}_{\mathrm{a}}(60 \mathrm{~min})$, was $3.57 \mathrm{wt} \% \mathrm{H}$ at $573 \mathrm{~K}$ and in 12 bar $\mathrm{H}_{2}$. It is believed that after reactive milling the PVDF became amorphous. The milling of $\mathrm{Mg}$ with the PVDF in hydrogen atmosphere is believed to have produced defects and cracks. The fabrication of defects is thought to ease nucleation. The fabrication of cracks is thought to expose fresh surfaces, resulting in an increase in the reactivity of the particles with hydrogen and a decrease in the diffusion distances of hydrogen atoms. As far as we know, this investigation is the first in which a polymer PVDF was added to $\mathrm{Mg}$ by reactive milling to improve the hydrogenation and dehydrogenation characteristics of $\mathrm{Mg}$.
\end{abstract}

(Received August 8, 2018; Accepted October 11, 2018)

Keywords: hydrogen absorbing materials, mechanical milling, scanning electron microscopy (SEM), X-ray diffraction, a polymer PVDF (polyvinylidene fluoride) addition

\section{INTRODUCTION}

Numerous approaches have been developed to store hydrogen as a potential compact energy source, including pressure storage, cryogenic storage, carbon nanotube storage, and metal hydride storage. Among these methods, metal hydride storage has several important advantages over the other methods. Metal hydride can store more hydrogen per unit volume than other methods, thereby allowing a more compact storage. It is considerably safer to use than pressure or cryogenic storage and only requires waste heat to release hydrogen from the hydride $[1,2]$.

As solid-state hydrogen storage materials, Magnesium, together with $\mathrm{Mg}_{2} \mathrm{Ni}, \mathrm{FeTi}$, and $\mathrm{LaNi}_{5}$ has drawn the attention of many researchers. Magnesium $(\mathrm{Mg})$ has a high theoretical

- 송명엽: 교수, 곽영준: 연구원

*Corresponding Author: Young Jun Kwak

[Tel: +82-63-270-2379, E-mail: twistking18@jbnu.ac.kr]

Copyright (c) The Korean Institute of Metals and Materials hydrogen storage capacity (7.66 wt\% on the basis of magnesium hydride $\left(\mathrm{MgH}_{2}\right)$ weight and $8.29 \mathrm{wt} \%$ on the basis of $\mathrm{Mg}$ weight). $\mathrm{Mg}$ is relatively inexpensive, and abundant in the earth's crust. However, the hydrogenation and dehydrogenation rates of $\mathrm{Mg}$ are low. A lot of work has been undertaken to increase the hydrogenation and dehydrogenation rates, and the hydrogen storage capacity of magnesium [3-13] by alloying certain metals with the magnesium [14-16], by synthesizing Mg-based compounds such as $\mathrm{Mg}_{2} \mathrm{Ni}$ [17-20], $\mathrm{Mg}_{51} \mathrm{Zn}_{20}$ [21], $\mathrm{LaMg}_{12}, \mathrm{CeMg}_{12}$ [22], $\mathrm{MmMg}_{12}$ (Mm: mischmetal), $\mathrm{La}_{2} \mathrm{Mg}_{17}$ [23], and $\gamma$ $\mathrm{Mg}_{17} \mathrm{Al}_{12}$ [24], by adding graphite to $\mathrm{Mg}$ [25], and by adding $\mathrm{Nb}$ and MWCNT (multi-walled carbon nanotubes) to alloys of $\mathrm{Mg}$ and $\mathrm{Ni}$ [26].

In our preceding works, the hydrogenation and dehydrogenation properties of $\mathrm{Mg}$ were improved by adding halogen compounds [27,28] such as fluorides $\left(\mathrm{NbF}_{5}[29]\right.$ and $\mathrm{TaF}_{5}$ [30]) and chlorides $\left(\mathrm{TiCl}_{3}\right.$ [31,32] and $\left.\mathrm{VCl}_{3}\right)$ via reactive milling. Decomposition at low temperatures of these 
halogen compounds is deemed to contribute to the improvement of the hydrogenation and dehydrogenation characteristics of $\mathrm{Mg}$.

Polyvinylidene fluoride (PVDF) is a highly non-reactive thermoplastic fluoropolymer produced by the polymerization of vinylidene difluoride. PVDF is a specialty plastic used in applications requiring the highest purity, as well as resistance to solvents, acids, and bases. Compared with other fluoropolymers, like polytetrafluoroethylene (Teflon), PVDF has a low density $\left(1.78 \mathrm{~g} / \mathrm{cm}^{3}\right)$. It has a relatively low melting point of around $450 \mathrm{~K}$. It is commonly used in the chemical, semiconductor, medical, and defense industries, as well as in lithium ion batteries [33]. In lithium ion batteries, it is used as a binder to fabricate the positive electrode.

The addition of PVDF was considered to have a possibility to improve the hydrogenation and dehydrogenation characteristics of $\mathrm{Mg}$. Since it has a relatively low density, a relatively small amount will have a relatively large volume. It is believed that the addition of even a small amount of PVDF can keep the $\mathrm{Mg}$ particles separated from one another. In this work, $95 \mathrm{wt} \% \mathrm{Mg}+5 \mathrm{wt} \%$ PVDF (designated Mg$5 \mathrm{PVDF}$ ) samples were prepared via milling in hydrogen atmosphere (reactive milling), and the hydrogenation and dehydrogenation characteristics of the prepared samples were compared with those of $\mathrm{Mg}$ milled in hydrogen atmosphere. As far as we know, this investigation is the first in which a polymer PVDF was added to $\mathrm{Mg}$ by reactive milling to improve the hydrogenation and dehydrogenation characteristics of $\mathrm{Mg}$.

\section{EXPERIMENTAL DETAILS}

Pure Mg powder (-20 +100 mesh, 99.8\%, metals basis, Alfa Aesar) and Polyvinylidene fluoride [PVDF, average Mw ca. 534000 (GPC), Aldrich] were the constituents of mixtures for the preparation of the Mg-5PVDF sample via reactive milling.

Samples were handled in argon atmosphere. The employed planetary ball mill was a Planetary Mono Mill (Pulverisette 6) from Fritsch. $8 \mathrm{~g}$ of planned mixtures were mixed with 105 hardened steel balls ( $360 \mathrm{~g})$. The disc rotation speed was 400 revolutions per minutes (rpm). The reactive milling was performed in hydrogen of about 12 bar for $12 \mathrm{~h}$. The period of refilling the mill container (with a volume of $250 \mathrm{~mL}$ ) with hydrogen was $2 \mathrm{~h}$.

The temperatures were kept constant at $573 \mathrm{~K}$ and $623 \mathrm{~K}$ to measure changes in the absorbed and released amounts of hydrogen, respectively, as a function of time. Changes in the absorbed and released hydrogen amounts with time were measured using a Sieverts' type hydrogenation and dehydrogenation apparatus explained previously [34]. A half gram of the samples was used for these measurements. For the hydrogenation, the hydrogen pressure was kept nearly constant in 12 bar by adding the amount of hydrogen absorbed by the sample from a standard reservoir (with a known volume) to the reactor. For the dehydrogenation, the hydrogen pressure was kept nearly constant in 1.0 bar by taking the amount of hydrogen released from the sample out of the reactor to the standard reservoir. After obtaining the released hydrogen amount as a function of time, the sample was vacuum-pumped at $623 \mathrm{~K}$ for $1 \mathrm{~h}$.

Phases in the samples after reactive milling and after hydrogenation-dehydrogenation cycling were analyzed by $\mathrm{X}$ ray diffraction (XRD) with $\mathrm{Cu} \mathrm{K} \alpha$ radiation, using a powder diffractometer (Rigaku D/MAX 2500). The scanning electron microscope (SEM) (JSM-5900), operated at $20 \mathrm{kV}$, was used to observe the microstructures of the Mg-5PVDF samples.

\section{RESULTS AND DISCUSSION}

Figure 1 shows a SEM micrograph of the PVDF, which was obtained with the scanning electron microscope JSM-

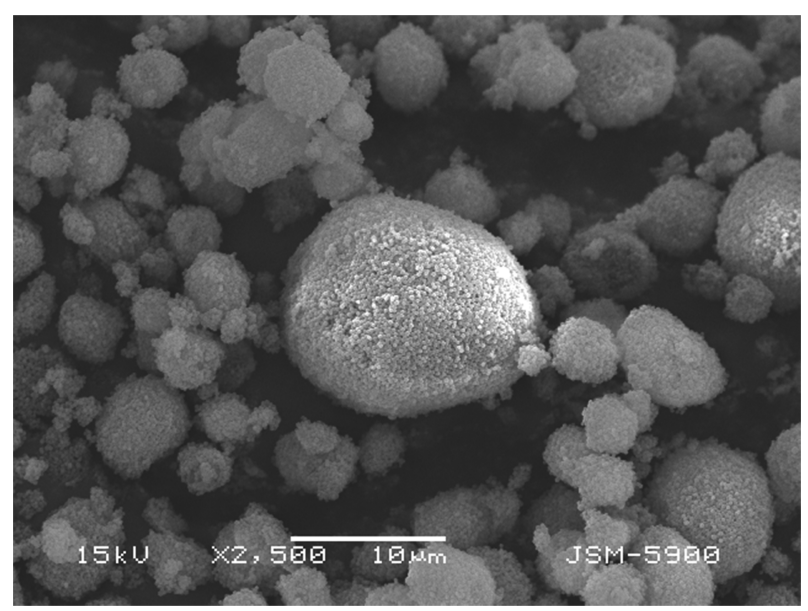

Fig. 1. A SEM micrograph of the PVDF. 

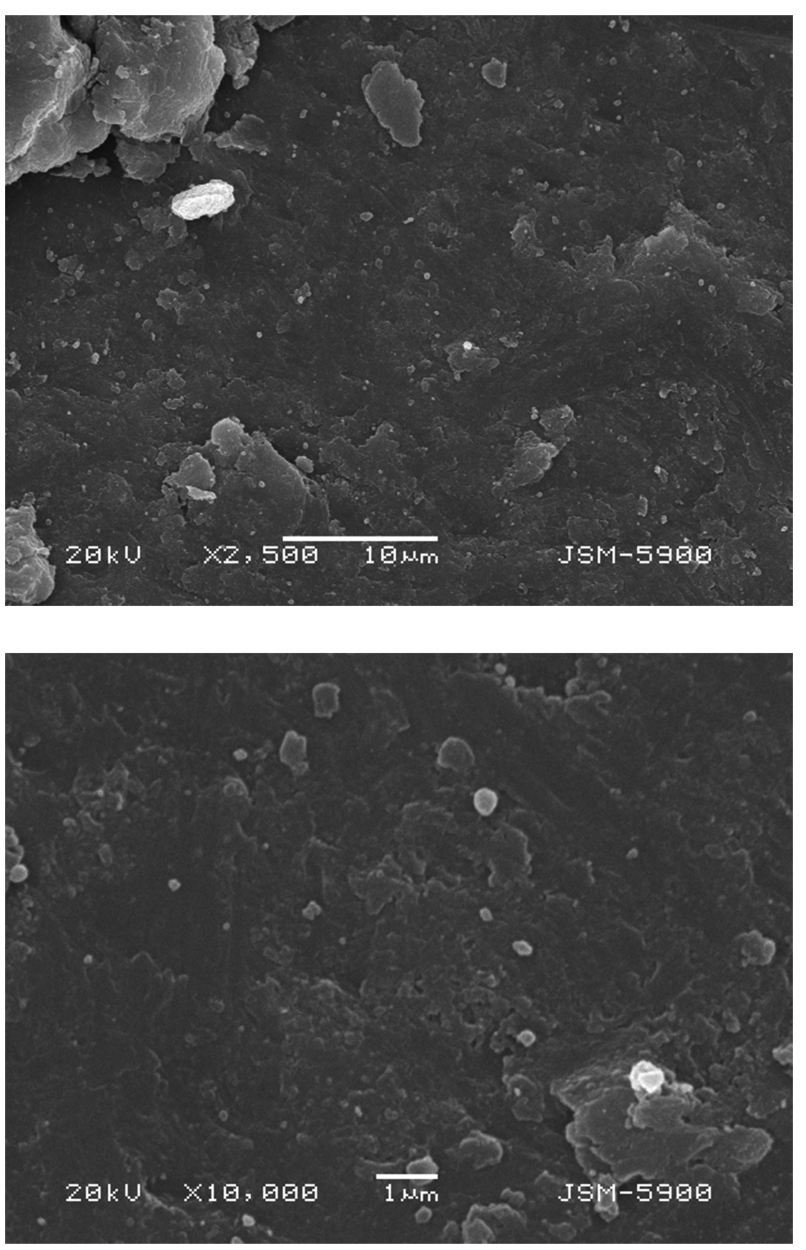

Fig. 2. SEM micrographs of the as-prepared Mg-5PVDF.

5900 operated at $15 \mathrm{kV}$. Agglomerates of the PVDF were spherical in shape and agglomerate sizes were not homogeneous. Agglomerates of the PVDF were composed of spherical fine particles. The XRD pattern of the PVDF exhibited sharp peaks and broad peaks, indicating that the PVDF was partly crystalline and partly amorphous. The XRD pattern of the PVDF was very similar to that of $\alpha$ PVDF reported by Martins et al. [35].

SEM micrographs of the as-prepared Mg-5PVDF are exhibited in Fig. 2. Particle sizes were not homogeneous. The surfaces of the particles were quite flat and some defects and cracks existed on the surfaces. During reactive milling, ductile $\mathrm{Mg}$ particles are believed to have been deformed plastically via collisions with the steel balls and the added PVDF is believed to have helped fine defects and cracks to form by repeated impact forces during ball milling.

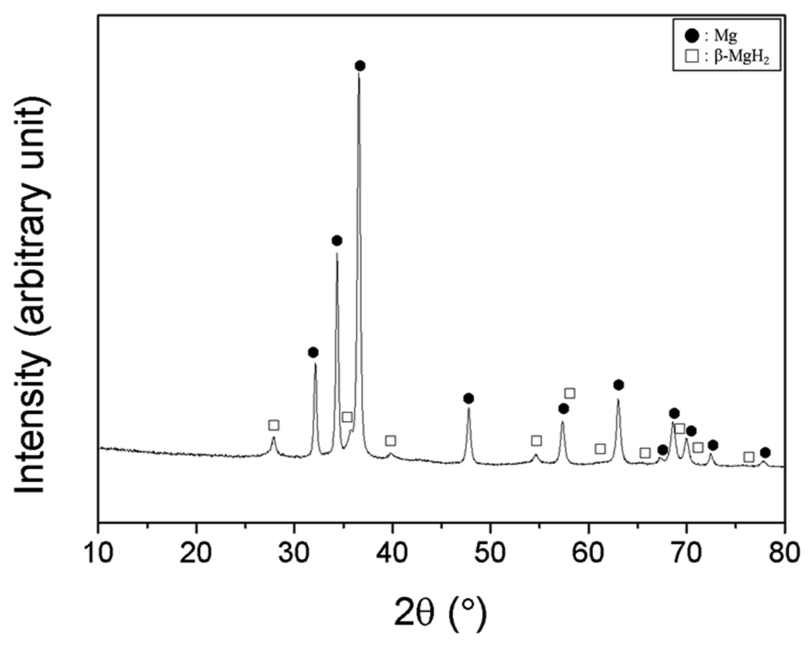

Fig. 3. The XRD pattern of the as-prepared Mg-5PVDF.

The XRD pattern of the as-prepared Mg-5PVDF is shown in Fig. 3. The Mg-5PVDF contained Mg and a small amount of $\beta-\mathrm{MgH}_{2}$. The peaks were sharp, showing that the Mg5PVDF was crystalline. No peaks for the PVDF were observed. The PVDF is believed to have become amorphous after reactive milling. It is believed that since the added quantity of the PVDF is small, the amorphous PVDF does not affect the form of the XRD pattern, especially the background of the XRD pattern.

The quantity of hydrogen released, $\mathrm{H}_{\mathrm{d}}$, was calculated using the sample weight as a criterion. $\mathrm{H}_{\mathrm{d}}$ was given in the unit of $\mathrm{wt}^{\mathrm{m}} \mathrm{H}$.

The released hydrogen quantity, $\mathrm{H}_{\mathrm{d}}$, versus temperature curve was obtained by heating the as-prepared $\mathrm{Mg}$-5PVDF at a heating rate of $5 \sim 6 \mathrm{~K} / \mathrm{min}$. From $681 \mathrm{~K}$ to $689 \mathrm{~K}$ the asprepared Mg-5PVDF sample released hydrogen very rapidly, showing that dehydrogenation of the magnesium hydride formed in the as-prepared Mg-5PVDF during reactive milling began at $681 \mathrm{~K}$. The total quantity of hydrogen released was $0.59 \mathrm{wt} \%$. This shows that $7.5 \%$ of the $\mathrm{Mg}$ in the Mg-5PVDF had been hydrogenated during reactive milling.

The quantity of hydrogen absorbed, $\mathrm{H}_{\mathrm{a}}$, was also calculated using the sample weight as a criterion. $\mathrm{H}_{\mathrm{a}}$ was also given in the unit of $\mathrm{wt} \% \mathrm{H}$.

The variation in the $\mathrm{H}_{\mathrm{a}}$ versus $\mathrm{t}$ curve at $573 \mathrm{~K}$ in 12 bar $\mathrm{H}_{2}$ with the number of cycles, $\mathrm{n}$, for the Mg-5PVDF is shown in Fig. 4. In $n=1$, the initial hydrogenation rate was slightly 


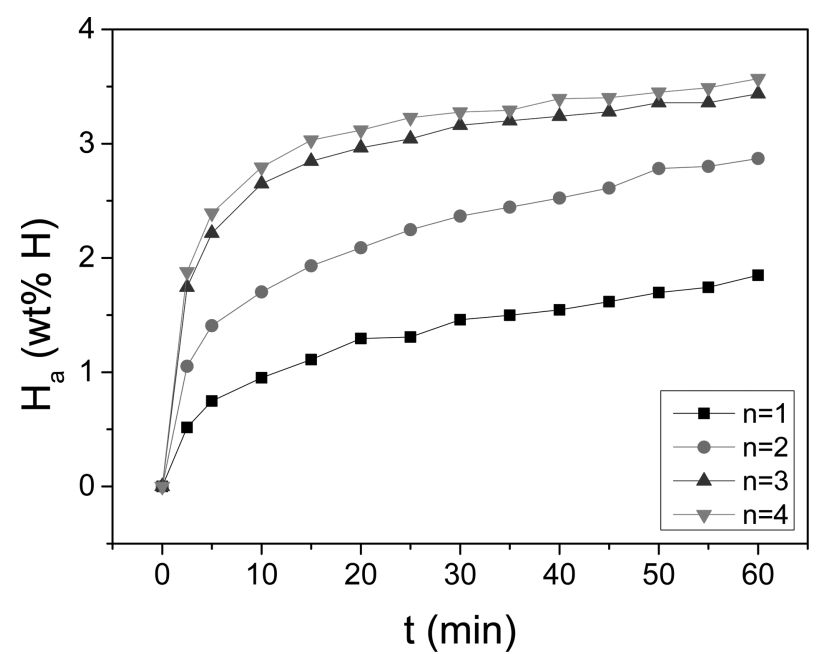

Fig. 4. Variation in the $\mathrm{H}_{\mathrm{a}}$ versus $\mathrm{t}$ curve at $573 \mathrm{~K}$ in 12 bar $\mathrm{H}_{2}$ with the number of cycles, $\mathrm{n}$, for the Mg-5PVDF.

high $(0.21 \mathrm{wt} \% \mathrm{H} / \mathrm{min})$ and the quantity of hydrogen absorbed for $60 \mathrm{~min}, \mathrm{H}_{\mathrm{a}}$ (60 min), was slightly large (1.85 $w t \% H)$. As $n$ increased from one to four, the initial hydrogenation rate and $\mathrm{H}_{\mathrm{a}}(60 \mathrm{~min})$ increased. The initial hydrogenation rate and $H_{a}(60 \mathrm{~min})$ in $n=4$ were slightly higher and larger, respectively, than those in $n=3$. At $n=4$, the initial hydrogenation rate was $0.75 \mathrm{wt} \% \mathrm{H} / \mathrm{min}$ and $\mathrm{H}_{\mathrm{a}}(60$ $\min$ ) was $3.57 \mathrm{wt} \% \mathrm{H}$.

$\mathrm{H}_{\mathrm{d}}$ (x min) indicates the quantity of hydrogen released for $x$ min. Figure 5 shows the variations in the $H_{d}(30 \mathrm{~min})$ and $\mathrm{H}_{\mathrm{d}}(60 \mathrm{~min})$ at $623 \mathrm{~K}$ in 1.0 bar $\mathrm{H}_{2}$ with the number of cycles, $n$, and the $\mathrm{H}_{\mathrm{d}}$ versus $\mathrm{t}$ curve at $623 \mathrm{~K}$ in 1.0 bar $\mathrm{H}_{2}$ in $\mathrm{n}=4$ for the Mg-5PVDF. $\mathrm{H}_{\mathrm{d}}$ (30 min) increased as $\mathrm{n}$ increased from one to two and $H_{d}(30$ min)'s in $n=3$ and $n=4$ were smaller than $H_{d}(30 \mathrm{~min})$ in $n=2 . H_{d}(60 \mathrm{~min})$ increased as $n$ increased from one to four and $H_{d}(60 \mathrm{~min})$ in $n=4$ was slightly larger than that in $n=3$. In $n=4$, the initial dehydrogenation rate was slightly high and the dehydrogenation rate at $5 \mathrm{~min}$ was lower than the initial dehydrogenation rate. The dehydrogenation rate then increased slowly and reached a maximum at about $30 \mathrm{~min}$. After about $30 \mathrm{~min}$ the dehydrogenation rate decreased gradually. In $n=4$, the initial dehydrogenation rate was 0.08 $\mathrm{wt} \% \mathrm{H} / \mathrm{min}$ and $\mathrm{H}_{\mathrm{d}}(60 \mathrm{~min})$ was $3.52 \mathrm{wt} \% \mathrm{H}$. The results in Fig. 4 and Fig. 5 show that the cycling effects on the initial hydrogenation and dehydrogenation rates, $\mathrm{H}_{\mathrm{a}}(60 \mathrm{~min})$, and $H_{d}(60 \mathrm{~min})$ were weak after $n=3$.

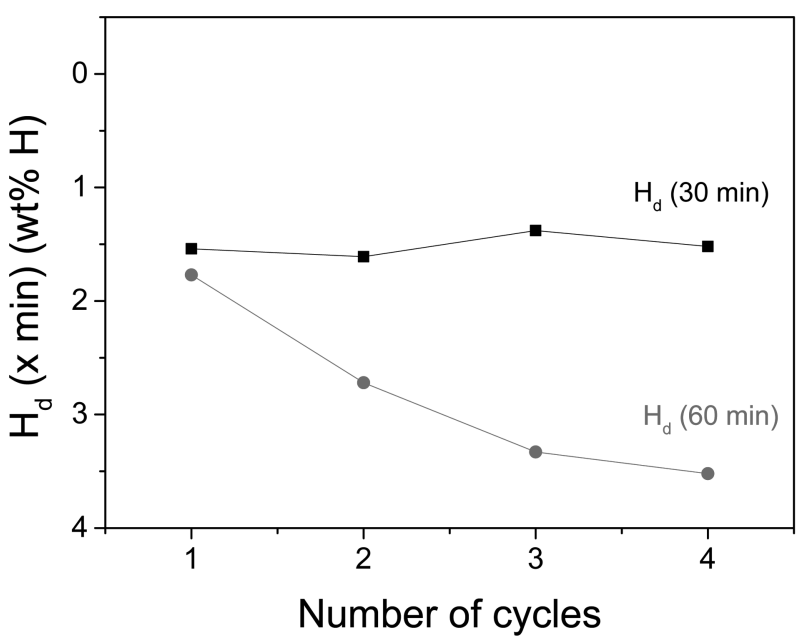

(a)

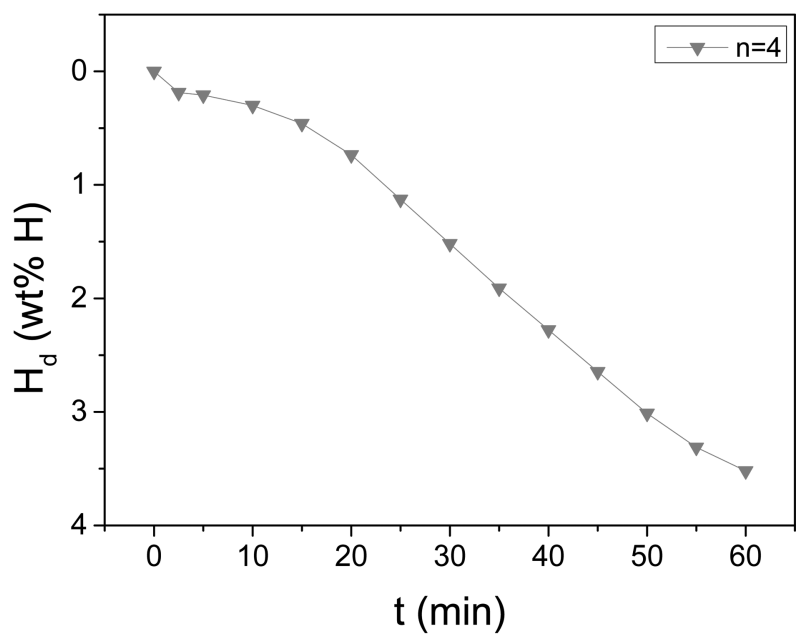

(b)

Fig. 5. (a) Variations in the $H_{d}(30 \mathrm{~min})$ and $H_{d}(60 \mathrm{~min})$ at $623 \mathrm{~K}$ in 1.0 bar $\mathrm{H}_{2}$ with the number of cycles, $n$, and (b) the $\mathrm{H}_{\mathrm{d}}$ versus $\mathrm{t}$ curve at $623 \mathrm{~K}$ in 1.0 bar $\mathrm{H}_{2}$ in $\mathrm{n}=4$ for the $\mathrm{Mg}-5 \mathrm{PVDF}$.

SEM micrographs of the Mg-5PVDF dehydrogenated in the fourth hydrogenation-dehydrogenation cycle are shown in Fig. 6. Particle sizes were not homogeneous. The surfaces of the particles were quite flat and some defects and cracks existed on the surfaces. Compared with the Mg-5PVDF after reactive milling, the $\mathrm{Mg}-5 \mathrm{PVDF}$ dehydrogenated at the fourth hydrogenation-dehydrogenation cycle had more defects and cracks.

Figure 7 shows the XRD pattern of the Mg-5PVDF dehydrogenated at $623 \mathrm{~K}$ in 1.0 bar $\mathrm{H}_{2}$ in the fourth hydrogenation-dehydrogenation cycle. This sample contained $\mathrm{Mg}$ and small amounts of $\beta-\mathrm{MgH}_{2}$ and $\mathrm{MgO} . \mathrm{MgO}$ is 

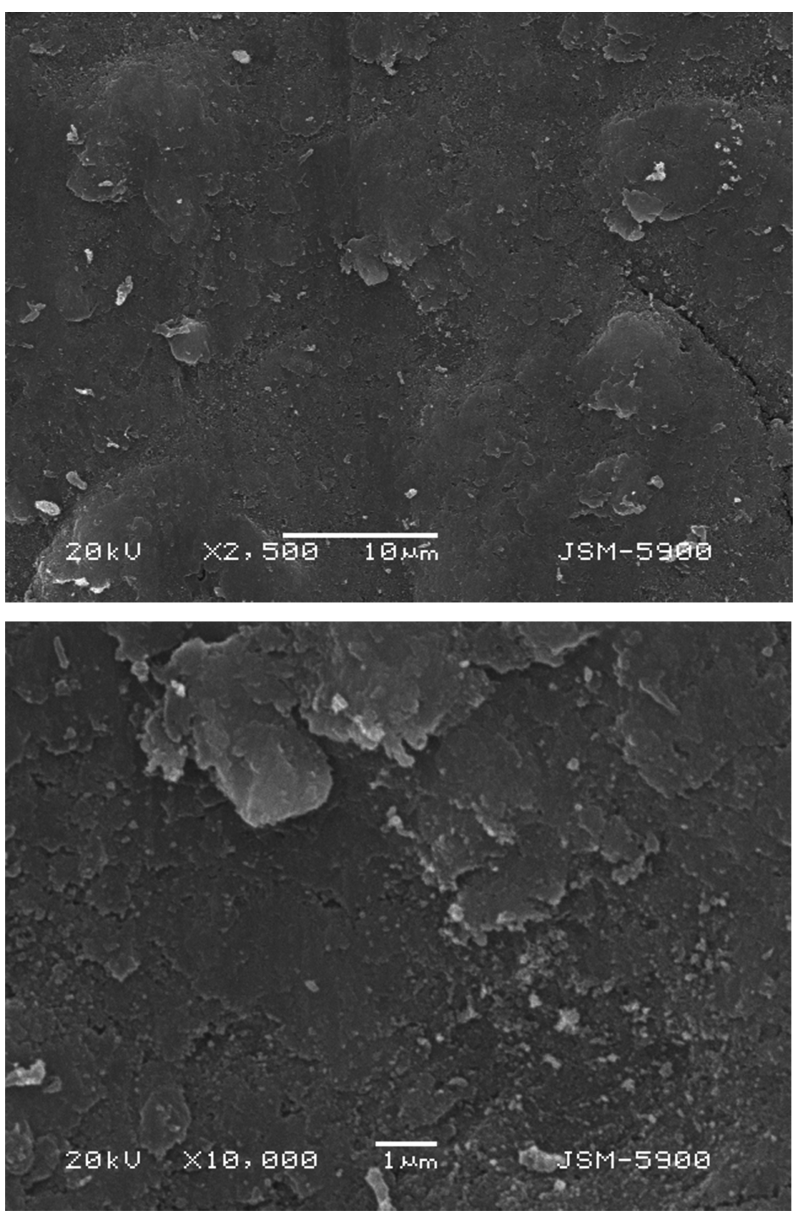

Fig. 6. SEM micrographs of the Mg-5PVDF dehydrogenated in the fourth hydrogenation-dehydrogenation cycle.

believed to have been formed by the reaction of $\mathrm{Mg}$ with oxygen adsorbed on the particles during being exposed to air while the samples were treated to obtain the XRD pattern.

The $\mathrm{H}_{\mathrm{a}}$ versus $\mathrm{t}$ curves at $573 \mathrm{~K}$ in 12 bar $\mathrm{H}_{2}$ in $\mathrm{n}=1$ and $\mathrm{n}=4$ for $\mathrm{Mg}$ after reactive milling are shown in Fig. 8. In $\mathrm{n}=1$, $\mathrm{Mg}$ after reactive milling did not absorb hydrogen. As $\mathrm{n}$ increased from one to four, the initial hydrogenation rate and $\mathrm{H}_{\mathrm{a}}(60 \mathrm{~min})$ increased. In $\mathrm{n}=4$, the initial hydrogenation rate was $0.12 \mathrm{wt} \% \mathrm{H} / \mathrm{min}$ and $\mathrm{H}_{\mathrm{a}}(60 \mathrm{~min})$ was $1.15 \mathrm{wt} \% \mathrm{H}$. The initial hydrogenation rates of the Mg-5PVDF were higher than those of $\mathrm{Mg}$ after reactive milling. The $\mathrm{H}_{\mathrm{a}}(60 \mathrm{~min})$ 's of the Mg-5PVDF were larger than those of Mg after reactive milling.

A SEM micrograph of Mg after reactive milling showed that during reactive milling, ductile $\mathrm{Mg}$ particles formed plastically into elongated and flat shapes via collisions with

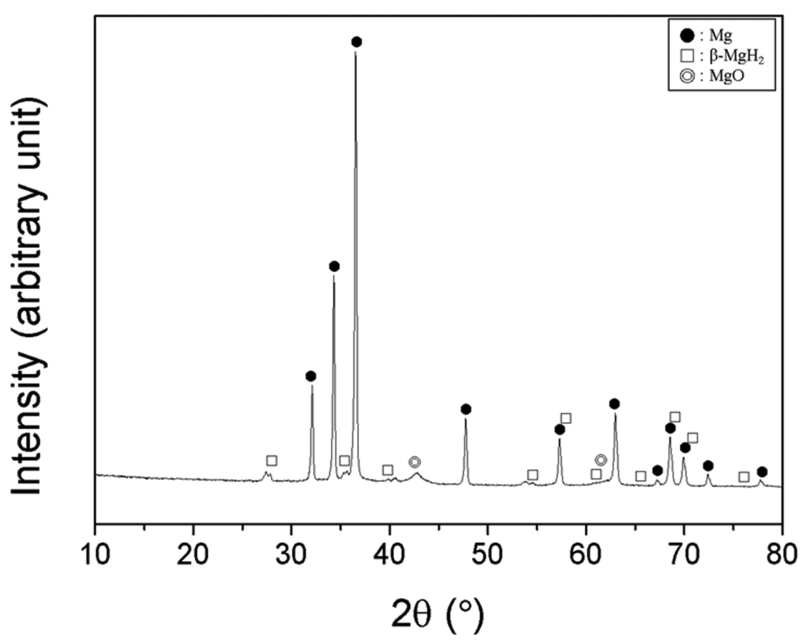

Fig. 7. The XRD pattern of the Mg-5PVDF dehydrogenated at 623 $\mathrm{K}$ in $1.0 \mathrm{bar}_{2}$ in the fourth hydrogenation-dehydrogenation cycle.

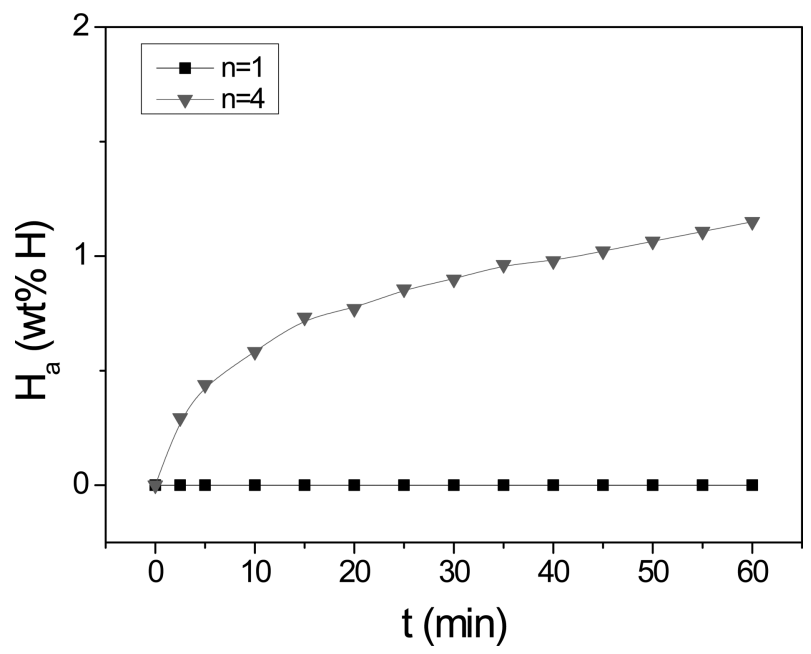

Fig. 8. $\mathrm{H}_{\mathrm{a}}$ versus $t$ curves at $573 \mathrm{~K}$ in 12 bar $\mathrm{H}_{2}$ in $\mathrm{n}=1$ and $\mathrm{n}=4$ for $\mathrm{Mg}$ after reactive milling.

the steel balls and no fine cracks formed by repeated impact forces during ball milling. Fine particles could not be obtained by reactive milling [36]. Therefore, $\mathrm{Mg}$ after reactive milling did not absorb hydrogen in the first cycle, as shown in Fig. 8.

The XRD pattern of the as-prepared Mg-5PVDF, shown in Fig. 3, revealed no phase related to the PVDF. The PVDF is believed to have become amorphous after reactive milling. The milling of Mg with the PVDF in hydrogen atmosphere is believed to have fabricated defects and cracks. The fabrication of defects is thought to ease nucleation. The fabrication of cracks is thought to expose fresh surfaces, 
resulting in an increase in the reactivity of particles with hydrogen and a decrease in the diffusion distances of hydrogen atoms [37,38]. Mechanical milling is reported to decrease particle size and to introduce defects into solid compounds [39]. Zhao et al. [40] reported the hydrogen storage properties of flexible and porous $\mathrm{La}_{0.8} \mathrm{Mg}_{0.2} \mathrm{Ni}_{3.8} /$ PVDF composite, insisting that in this composite, the PVDF acted as a binder to connect the alloy particles and $\left(\mathrm{NH}_{4}\right)_{2} \mathrm{CO}_{3}$ as a pore-forming agent to create void space. They reported that the PVDF-assisted composite showed the flexible/solidified characteristic in hydrogenation/dehydrogenation, which might have lowered the oxidation of the alloy particles and preserved the void space [40]. Han et al. [41] derived porous carbons from the PVDF by thermal decomposition at various carbonization temperatures. They reported that the PVDFderived porous carbon (PPC) samples showed hydrogen storage capacities of up to $2.02 \mathrm{wt} \% \mathrm{H}$ at $77 \mathrm{~K}$ in 1 bar $\mathrm{H}_{2}$ and that the textural properties of the PPC samples, such as the specific surface area, pore size, and pore volume, are key factors in improving their hydrogen storage capacity [41]. Yuan et al. [42] prepared an Mg-based hydrogen storage composite by adding 5 and $10 \mathrm{wt} \%$ polymethyl methacrylate (PMMA) to a hydriding combustion synthesized $\mathrm{Mg}_{95} \mathrm{Ni}_{5}$ alloy. They reported that the polymer PMMA acted as the nano-dispersion controller in the mechanical milling process and made the $\mathrm{Mg}_{95} \mathrm{Ni}_{5}$ have a smaller average grain size and a larger amount of defects. $\mathrm{Mg}_{95} \mathrm{Ni}_{5}-10$ wt $\%$ PMMA absorbed $3.37 \mathrm{wt} \% \mathrm{H}$ at $473 \mathrm{~K}$ for $60 \mathrm{~min}$ and $2.5 \mathrm{wt} \% \mathrm{H}$ at $523 \mathrm{~K}$ for $60 \mathrm{~min}$. The nanocomposite desorbed $1.02 \mathrm{wt} \% \mathrm{H}$ within $120 \mathrm{~min}$ at $473 \mathrm{~K}$ and $2.18 \mathrm{wt} \% \mathrm{H}$ within $120 \mathrm{~min}$ at $523 \mathrm{~K}$.

The XRD patterns of other samples after reactive milling exhibited peak broadening and increases in the background [28-31]. However, the XRD pattern of the Mg-5PVDF after reactive milling showed very small peak broadening and a very small increase in the background. The XRD pattern of the Mg-5PVDF dehydrogenated at $623 \mathrm{~K}$ in hydrogen of 1.0 bar in the fourth hydrogenation-dehydrogenation cycle was very similar to that of the Mg-5PVDF after reactive milling. These results suggest that the reactive milling of $\mathrm{Mg}$ with 5 wt $\%$ PVDF induced very small strain.

The results in Fig. 4 showed that hydrogenationdehydrogenation cycling increased the initial hydrogenation rate and $\mathrm{H}_{\mathrm{a}}(60 \mathrm{~min})$ until the completion of activation, probably due to the repetition of the expansion (by hydrogenation) and contraction (by dehydrogenation) of the material. The expansion and contraction are deemed to have generated defects and produced cracks.

\section{CONCLUSIONS}

In this work, $95 \mathrm{wt} \% \mathrm{Mg}+5 \mathrm{wt} \%$ PVDF (designated Mg5PVDF) samples were prepared via milling in hydrogen atmosphere (reactive milling), and the hydrogenation and dehydrogenation characteristics of the prepared samples were compared with those of $\mathrm{Mg}$ milled in hydrogen atmosphere. As far as we know, this investigation is the first in which the polymer PVDF was added to $\mathrm{Mg}$ by reactive milling to improve the hydrogenation and dehydrogenation characteristics of $\mathrm{Mg}$. The dehydrogenation of magnesium hydride formed in the as-prepared $\mathrm{Mg}-5 \mathrm{PVDF}$ during reactive milling began at $681 \mathrm{~K}$. In the fourth cycle $(\mathrm{n}=4)$, the initial hydrogenation rate was $0.75 \mathrm{wt} \% \mathrm{H} / \mathrm{min}$ and $\mathrm{H}_{\mathrm{a}}(60 \mathrm{~min})$ was $3.57 \mathrm{wt} \% \mathrm{H}$. The PVDF is believed to have become amorphous after reactive milling. The milling of $\mathrm{Mg}$ with the PVDF in hydrogen atmosphere is believed to have fabricated defects and cracks. Fabrication of defects is considered to ease nucleation. Fabrication of cracks is thought to expose fresh surfaces, resulting in an increase in the reactivity of the particles with hydrogen and a decrease in the diffusion distances of hydrogen atoms. The repetition of the expansion (by hydrogenation) and contraction (by dehydrogenation) of the material are deemed to have generated defects and produced cracks.

\section{REFERENCES}

1. S. H. Hong, Y. J. Kwak, and M. Y. Song, Korean J. Met. Mater. 56, 59 (2018).

2. S. H. Hong and M. Y. Song, Korean J. Met. Mater. 56, 155 (2018).

3. S. H. Lee, Y. J. Kwak, H. R. Park, and M. Y. Song, J. Nanosci. Nanotech. 15, 8777 (2015).

4. Y. J. Kwak, S. H. Lee, B. S. Lee, H. R. Park, and M. Y. Song, J. Nanosci. Nanotech. 15, 8763 (2015).

5. S. H. Hong and M. Y. Song, Met. Mater. Int. 22, 544 (2016).

6. M. Y. Song, Y. J. Kwak, S. H. Lee, and H. R. Park, J. 
Nanosci. Nanotech. 16, 10499 (2016).

7. S. H. Hong and M. Y. Song, Met. Mater. Int. 22, 1121 (2016).

8. H. R. Park, Y. J. Kwak, S. H. Lee, and M. Y. Song, Korean J. Met. Mater. 54, 916 (2016).

9. Y. J. Kwak, H. R. Park, and M. Y. Song, Int. J. Hydrogen Energy 42, 1018 (2017).

10. M. Y. Song and Y. J. Kwak, Korean J. Met. Mater. 56, 244 (2018).

11. Y. J. Kwak, H. R. Park, and M. Y. Song, Met. Mater. Int. 22, 423 (2018).

12. M. Y. Song, E. Choi, and Y. J. Kwak, Korean J. Met. Mater. 56, 392 (2018).

13. M. Y. Song, Y. J. Kwak, and E. Choi, Korean J. Met. Mater. 56, 524 (2018).

14. M. Y. Song, Int. J. Hydrogen Energy 20, 221 (1995).

15. M. Y. Song, J. Mater. Sci. 30, 1343 (1995).

16. S. N. Kwon, H. R. Park, and M. Y. Song, Korean J. Met. Mater. 54, 510 (2016).

17. M .Y. Song, M. Pezat, B. Darriet, J. Y. Lee, and P. Hagenmuller, J. Mater. Sci. 21, 346 (1986).

18. M. Y. Song, B. Darriet, M. Pezat, J. Y. Lee, and P. Hagenmuller, J. Less-Common Met. 118, 235 (1986).

19. M. Y. Song, B. Darriet, M. Pezat, and P. Hagenmuller, Int. J. Hydrogen Energy 12, 27 (1987).

20. H. R. Park, Y. J. Kwak, and M. Y. Song, Mater. Res. Bull. 99, 23 (2018).

21. M. Y. Song, H. R. Park, Int. J. Hydrogen Energy 18, 653 (1993).

22. J. M. Boulet and N. Gerard, J. Less-Common Met. 89, 151 (1983).

23. M. Khrussanova, M. Pezat, B. Darriet, and P. Hagenmuller, J. Less-Common Met. 86, 153 (1982).

24. S. Bouaricha, J. P. Dodelet, D. Guay, J. Hout, S. Boily, and R. Schulz, J. Alloy. Compd. 297, 282 (2000).

25. H. Imamura, Y. Takesue, T. Akimoto, and S. Tabata, J.
Alloy. Compd. 293-295, 564 (1999).

26. S. Aminorroaya, A. Ranjbar, Y. H. Cho, H. K. Liu, and A. K. Dahle, Int. J. Hydrogen Energy 36, 571 (2011).

27. Y. J. Kwak, S. H. Lee, H. R. Park, and M. Y. Song, J. Nanosci. Nanotech. 16, 10508 (2016).

28. M. Y. Song and Y. J. Kwak, Korean J. Met. Mater. 56, 611 (2018).

29. S. H. Lee, Y. J. Kwak, H. R. Park, and M. Y. Song, Int. J. Hydrogen Energy 39, 16486 (2014).

30. S. H. Lee, Y. J. Kwak, H. R. Park, and M. Y. Song, Korean J. Met. Mater. 52, 957 (2014).

31. S. H. Lee, Y. J. Kwak, H. R. Park, and M. Y. Song, Korean J. Met. Mater. 53, 187 (2015).

32. H. R. Park, S. H. Lee, and M. Y. Song, J. Ceram. Process. Res. 17, 1292 (2016).

33. https://en.wikipedia.org/wiki/Polyvinylidene_fluoride

34. M. Y. Song, Y. J. Kwak, S. H. Lee, and H. R. Park, Korean J. Met. Mater. 54, 210 (2016).

35. P. Martins, A. C. Lopes, and S. Lanceros-Mendez, Prog. Polym. Sci. 39, 683 (2014).

36. M. Y. Song, Y. J. Kwak, S. H. Lee, and H. R. Park, Bull. Mater. Sci. 37, 831 (2014).

37. H. R. Park, Y. J. Kwak, S. H. Lee, and M. Y. Song, Korean J. Met. Mater. 54, 916 (2016).

38. H. R. Park, Y. J. Kwak, and M. Y. Song, Korean J. Met. Mater. 55, 656 (2017).

39. R. A. Varin, T. Czujko, and Z. S. Wronski, Nanomaterials for Solid State Hydrogen Storage, p. 38, Springer, New York (2009).

40. Z. Zhao, M. Qin, Y. Jia, Y. Chai, D. Hou, and N. Wang, Int. J. Hydrogen Energy 38, 10939 (2013).

41. Y.-J. Han, S.-J. Park, J. Nanosci. Nanotech. 17, 8075 (2017).

42. J. G. Yuan, Y. F. Zhu, L. Q. Li, Y. Wu, and S. X. Zhou, Int. J. Hydrogen Energy 42, 22366 (2017). 